\title{
Comprehensive grouping efficacy: A new measure for evaluating block-diagonal forms in group technology
}

\author{
Adnan Mukattash $^{a^{*}}$, Nadia Dahmani ${ }^{\mathrm{a}, \mathrm{b}}$, Adnan Al-Bashir ${ }^{\mathrm{c}}$ and Ahmad Qamar
}

${ }^{a}$ Department of Industrial Management, Emirates College of Technology, Abu Dhabi, UAE

${ }^{b}$ LARODEC Laboratory, Institut Superieur de Gestion, 2000 Le Bardo, Tunisia

${ }^{c}$ Department of Industrial Engineering, Faculty of Engineering, Hashemite University, Zarka Jordan

\section{H R O N I C L E \\ A B S T R A C T}

Article history:

Received October 272016

Received in Revised Format

December 252016

Accepted March 122017

Available online

March 142017

Keywords:

Cell Size

Grouping measures

Sparsity

Sparsity index

Comprehensive

Grouping measure

Efficiency index

\begin{abstract}
The goodness of machine-part groups in cellular manufacturing systems is evaluated by different measures available in the literature. The commonly known grouping efficiency measures will be discussed in this paper. None of these measures has the ability to evaluate the efficiency of block -diagonal system and sub-system at the same time. Moreover, sparsity of individual cells was not taken into consideration in these measures. In this paper, a new grouping measure called Comprehensive Grouping Efficacy (CGE) is proposed to overcome the drawbacks of these measures. CGE is tested against some problems from the literature and the results demonstrate the ability of this measure to be used as comprehensive grouping measure since four of the wellknown measures are included in the CGE formula. The superiority of CGE is that it can be used to find the efficiency of block-diagonal form, the efficiency of sub-system, sparsity index and efficacy index at the same time, which will give the designer the opportunity to control the cell size. Without knowing the efficiency of sub-systems (individual cells), the system designer will not be able to control the cell size.
\end{abstract}

\section{Introduction}

Group technology (GT) is a method of organizing and using information about component similarities to improve the production efficiency of small to medium batch oriented manufacturing systems (Askin \& Chiu, 1990). The main idea of GT is to capitalize on similar manufacturing processes and features where similar parts are grouped into a part family and manufactured by a cluster of dissimilar machines ( $\mathrm{Wu}, 1998)$. The input to the GT problem is a zero-one matrix $A$ where $a_{\mathrm{ij}}=1$ indicates the visit of component $j$ to machine $i$, and $\mathrm{a}_{\mathrm{ij}}=0$ otherwise. Grouping of components into families and machines into cells results in a transformed matrix with diagonal-blocks where ones occupy the diagonal-blocks and zeros occupy the off-diagonal blocks. The resulting diagonal blocks represent the manufacturing cells. Cellular manufacturing (CM) is an important application of group technology (GT) in which sets

* Corresponding author

E-mail: adnan.muqatash@ect.ac.ae (A. Mukattash)

(C) 2017 Growing Science Ltd. All rights reserved. doi: 10.5267/j.ijiec.2017.3.006 
(families) of parts are produced on a group of various machines, which are physicaly close together and can entirely process a family of parts. The identification of part families and machine groups in the design of cellular manufacturing systems is commonly referred to as cell design/formation (Mansouri et al., 2000). Algorithms that aim at forming the part families and machine cells essentially try to rearrange the rows and columns of part/machine incidence matrix to get a block-diagonal form. Different methods are available in the literature (Elbenani, \& Ferland, 2012; Brusco, 2015; Bychkov, et al., 2014; Ghosh et al., 2014; Murugan \& Selladurai 2011; Bottani et al., 2017; Rezazadeh \& Khiali-Miab, 2017; Rabbani et al., 2017). The size of each cell, measured by the number of machines allocated to the cell, is a variable that needs to be controlled. There are several reasons (e.g. available space and visible control requirements) that might impose an upper limit on the number of machines. Also, it is not usual to construct a cell of one or two machines. This may lead to a very low utilization of the cell's handling and loading equipment. That is why there must be an upper and lower bounds on cell size (Boctor, 1996). The ideal situation is the one in which all the ones are in the diagonal-blocks and all the zeros are in the off-diagonal blocks. However, the ideal case seldom occurs in for a real shop floor problem (Kumar \& Chandrasekharom, 1990). The structure of the final machine-component matrix significantly affects the effectiveness of the corresponding cellular manufacturing system (Seifoddini \& Djassem, 1996). For this reason the choice of grouping methodology must be based on criteria that can indicate the goodness of a grouping solution. Hence, a number of grouping measures have been developed to evaluate the efficiency of block-diagonal forms. Some of these measures are, Grouping capability index (GCI) (Hsu, 1990), Global efficiency (GLE) (Harhalakis et al., 1990), Grouping measure (Miltenburg \& Zhang, 1991), Weighted Grouping Efficiency (Sarkar \& Khan, 2001) and Double weighted grouping efficiency (Sarkar, 2001), GT efficacy (Kichun \& Ahn, 2013), Modified grouping efficacy (Rajesh et al., 2016). Some other well-known measures will be discussed below in section 2. For other measures that are available in the literature see (Sarker \& Mondal, 1999; Sarker \& Khan, 2001, Sarker, 2001; Keeling et al., 2007, Agrawal et al., 2011, Kichun \& Kwang-Il, 2013). Kichun Lee and Kwang-Il Ahn (2013) pointed out that, grouping efficacy is used as a standard measure for evaluating solutions based on a binary part-machine matrix.

None of the above mentioned measures can evaluate the efficiency of block-diagonal system and subsystem at the same time which means that, these measures do not have the ability to determine (or quantify) the quality of individual cells inside the matrix. Moreover, sparsity of individual cells was not taken into consideration in these measures and none of these measures can provide the system designer with any cell indicator that can help him to control the cell size.

This paper introduces a new measure called Comprehensive Grouping Efficacy (CGE) which is considered to be more accurate to determine the efficiency of a block-diagonal form for developing cellular manufacturing systems. The main features of CGE measure are: First, CGE can find the efficiency of block-diagonal system and, at the same time, it can reflect the goodness of every cell by taking into consideration the number of operations, number of voids, number of exceptional parts, cell size (sparsity of individual cell in the solved matrix) and sparsity of the system regardless of the size of the matrix. Second, CGE is a comprehensive grouping measure since it can be used to find the efficiency of block-diagonal system and/or cell utilization and/or machine utilization and/or cell indicator and/or cell flexibility at the same time. Finally, CGE will provide the designer with three indicators (sparsity index, efficacy index and efficiency of individual cells in the solved matrix) to control the cell size.

The following definitions will be used in this paper:

Block: A sub-matrix of the machine component incidence matrix formed by the intersection of columns representing a component family and rows representing a machine cell.

Voids: A zero element appearing in a diagonal block.

Exceptional element (or exception): The one appearing in the off-diagonal blocks.

Perfect block-diagonal form: The block-diagonal form in which all diagonal blocks contain ones and all off-diagonal blocks contain zeros (Kumar \& Chandrasekhoran, 1990). 
Sparsity (Block- diagonal space): Total number of elements within the diagonal blocks of the solved matrix (Sarker \& Khan, 2001).

\section{Literature Review}

The commonly known grouping efficiency measures in the literature can be classified into two groups based on the efficiency evaluation of block-diagonal forms and evaluation of individual cells.

\subsection{Efficiency evaluation of block-diagonal forms}

These measures are developed to evaluate the efficiency of block-diagonal forms. Some of these measures are listed below.

- Grouping Efficiency (ๆ): (Chandrasekhoran \& Rajogopalan, 1986)

The main drawbacks of GE have been exposed already in earlier studies (for more details see Kumar and Chandrasekharan (1990), Sarker and Mondal (1999), Sarker and Khan (2001) and Sarker (2001)). It is defined as:

Grouping Efficiency $=q \eta_{1}+(1-q) \eta_{2}$

where $\eta_{1}=\frac{e_{d}}{\left(\sum_{r=1}^{k} M_{r} N_{r}\right)}$ and $\eta_{2}=1-\frac{e_{o}}{\left(\sum_{r=1}^{k} M_{r} N_{r}\right)}$.

$\mathrm{e}_{\mathrm{d}}=$ total number of operations in the Machine-Part (MP) matrix, $\mathrm{e}_{0}=$ number of exceptions,

$\mathrm{e}_{\mathrm{v}}=$ number of voids,

$\mathrm{q}=$ weighted factor, $\quad 0 \leq \mathrm{q} \leq 1$

$\mathrm{m}=$ total number of parts in the matrix,

$\mathrm{n}=$ total number of machines in the matrix.

- Machine Utilization (MU): (Chandrasekharan \& Rajagopalan, 1986)

The main drawbacks of $\mathbf{M U}$ are that number of voids and exceptions are not taken into consideration.

$$
M U=\frac{N_{1}}{\sum_{c=1}^{c} m_{c} n_{c}},
$$

where

$N_{1}$ : total number of $1, \mathrm{~s}$ in the diagonal blocks of the machine-part incident matrix, $n_{c}$ :total number of parts in the cth cell,

$m_{c}$ :total number of machines in the cth cell.

- $\quad$ Grouping Efficacy $(\tau)$ : (Suresh Kumar \& Chandrasekharan, 1990)

To overcome the problems of $(\eta)$, grouping efficacy has been introduced. The most used measure in the literature is the Grouping efficacy. The main drawback of $(\tau)$ is that, sparsity of the individual cells size is not taken into consideration. Grouping efficacy $(\tau)$ is defined as: 


$$
\tau=\frac{1-\Psi}{1+\phi},
$$

where $\Psi=\frac{\text { Number of exceptional elements }}{\text { Total number of operations in the MP matrix }}$ and $\phi=\frac{\text { Number of voids in the diagonal blocks }}{\text { Total number of operations in the MP marix }}$.

$$
\tau=\frac{\mathrm{k}}{\mathrm{k}+v+\mathrm{e}_{0}}
$$

$\mathrm{k}+\mathrm{e}$ : total number of operations in the MP matrix,

$\mathrm{k}$ : number of operations in the diagonal block,

e: number of exceptions,

v: number of voids.

- Weighted grouping efficacy $(\omega):(\mathrm{Ng}, 1993)$

The main drawback of $(\omega)$ is that, sparsity of the individual cells size is not taken into consideration

$$
\omega=\frac{q\left(e-e_{0}\right)}{q\left(e+e_{v}-e_{0}\right)+(1-q) e_{0}}
$$

where e: total number of operations in the MP matrix, $\mathrm{e}_{0}$ : number of exceptions, $\mathrm{e}_{\mathrm{v}}$ : number of voids, q:weighted factor.

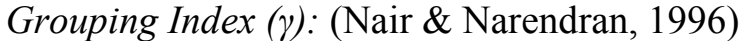

$\gamma$ is derived from the modified grouping efficacy by introducing a correction factor. The main drawback of $(\gamma)$ is that, sparsity of the individual cells in the solved matrix is not taken into consideration

$$
\gamma=\frac{1-\frac{q e v+(1-q)\left(e_{0}-A\right)}{B}}{1+\frac{q e v+(1-q)\left(e_{0}-A\right)}{B}},
$$

where $A=0$ for $e 0 \leq B$ and $A=e 0-B$ for $e 0$ greater than $B$ can be written as follows,

$\gamma=\frac{1-\alpha}{1+\alpha}$,where $\quad \alpha=\frac{q e_{v}+(1-q)(e 0-A)}{B}$ and $\gamma=\frac{1-\alpha}{1+\alpha}$,where $\quad \alpha=\frac{q e_{v}+(1-q)(e 0-A)}{B}$ and A is a correction factor and $B$ is the sparsity of the solved matrix and $e_{0}$ is the number of exceptions, $e_{\mathrm{v}}$ is the number of voids and $q$ is the weighted factor.

- $\quad$ Modified grouping efficacy $\left(\tau_{2}\right)$ : (Nair \& Narendran, 1996)

The main drawback of this measure is that, sparsity of the individual cells in the solved matrix is not taken into consideration.

$$
\tau_{2}=\frac{B-q e_{v}+(1-q) e_{0}}{B+q e_{v}+(1-q) e_{0}},
$$

where $B$ is the sparsity of the solved matrix, $e_{0}, e_{v}$ and $q$ represent, the number of voids, the weighted factor and the number of exceptions, respectively. 


\subsection{Evaluation of the individual cells in the solved matrix}

These measures are developed to evaluate the individual cells in the solved matrix. Some of these measures are listed below.

- $\quad$ Cell Utilization (CU): (Mahdavi et al., 2007)

CU does not take into consideration the exceptional elements of the formed cells. This measure is used only to determine the utilization of individual cells inside the solved matrix. Cell utilization is defined as a number of non-zero elements of block-diagonal divided by block-diagonal matrix size of each cell. Cell Utilization can be written as:

$$
C U_{k}=\frac{\text { Number of Opoerations in cell } k}{\text { Block-diagonal Matrix Size of cell } k}
$$

CU doesn't take into consideration the exceptional elements of the formed cells.

- $\quad$ Cell Indicator $(\alpha)$ : (Al-Bashir et al., 2016)

This measure is used only to determine the cell indicator of individual cells inside the solved matrix. The effect of individual cell size is not taken into consideration in this measure.

$$
\alpha_{p}=\frac{v_{p}+e_{p}}{k_{p}},
$$

where $\alpha_{p}, v_{p}, e_{p}$ and $k_{p}$ represent cell indicator of the $p^{\text {th }}$ cell, the number of voids in $p^{\text {th }}$ diagonal block, the number of exceptional elements in the $p^{\text {th }}$ off-diagonal block and the number of operations in the $p^{\text {th }}$ diagonal block, respectively.

- $\quad$ Measure of Flexibility (MF): (Nagendra, 2004c)

This measure is used only to determine the average measure of flexibility of individual cells inside the solved matrix. The effect of individual cell size is not taken into consideration in this measure.

$$
M F=\frac{N O_{k}}{\sum_{k=1}^{n c}\left(m_{k} \times c_{k}\right)},
$$

where $N O_{k}, m_{k}, c_{k}$ and $n_{c}$ represent the number of operations executed in the $\mathrm{k}^{\text {th }}$ cell, the number of machines in the kth cell, the number of components in the kth cell and the number of cells, respectively. Since $M F$ varies from cell to cell, for evaluation purposes, the average measure of the flexibility is computed as follows,

$$
A M F=\left[\frac{M F}{n_{c}}\right] \times 100,
$$

where $n_{c}$ is the number of cells formed. Obviously, higher values of AFM represents higher flexibility.

\section{Illustration 1 :}

Consider the solution matrix of Table 1(Al-Basher et al., 2016), which contains twelve machines and twelve parts. This case study will be used to clarify the difference between the two groups of the evaluation measures of both block-diagonal forms and individual cells (Eqs. 1-11). 


\section{Table 1}

Final solution for illustration 1

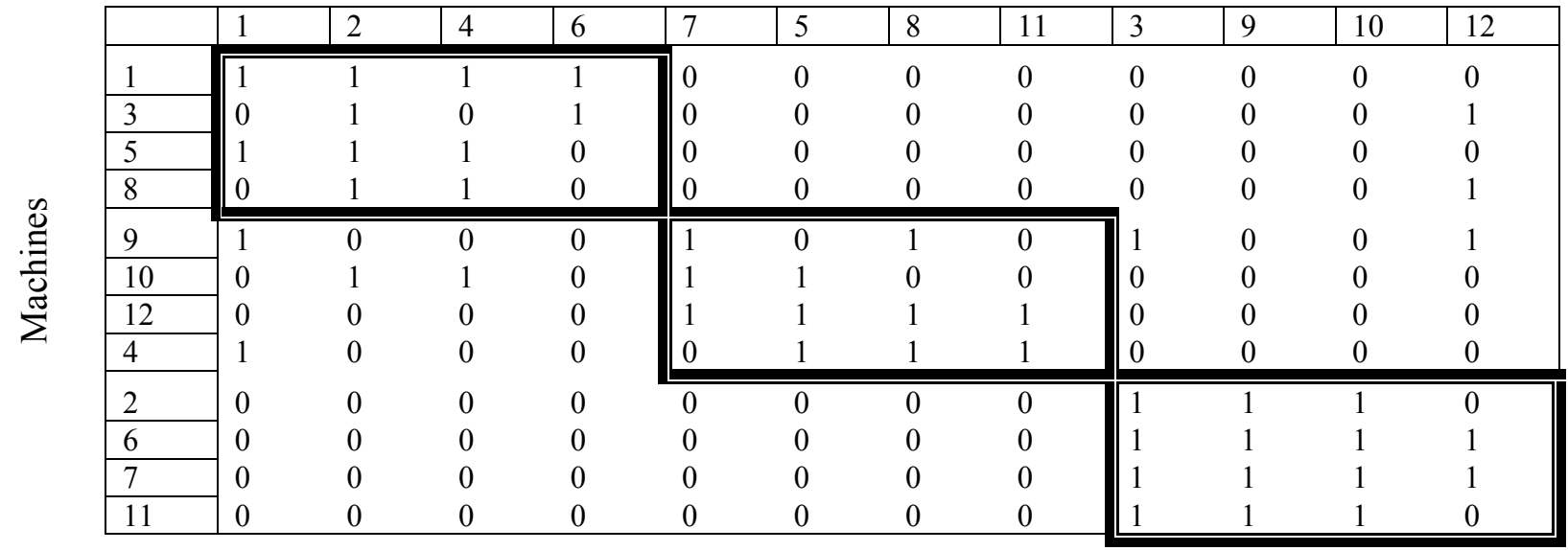

Assume that the system designer wants to find the efficiency of the system shown in Table 1; in this case one of the formulas shown in Eqs. (1-7) will be used. Suppose that grouping efficacy measure is used (Eq. 3), the result will be as shown in Table 2. Moreover, if the designer wants to evaluate the individual cells, in this case he/she will choose one of the formulas shown in Eqs. (8-11). Assume that cell utilization is used (Eq. 8), the results are shown in Table 2. We can conclude that, the designer has to use two different formulas from the above two groups to find the efficiency of block -diagonal system and to evaluate the individual cells.

Table 2

Cell utilization and grouping efficacy - problem Table 1

\begin{tabular}{lcccc}
\hline Cell utilization & Cell 1 & Cell 2 & Cell 3 & Grouping Efficacy $(\tau)$ \\
\hline Solution & 0.6875 & 0.6875 & 0.875 & 0.64 \\
\hline
\end{tabular}

To avoid using two different formulas, a new Comprehensive Grouping Efficacy (CGE) measure is developed in this paper shown in Eq. (13). CGE measure can be:

1. Rewritten in four different forms to :

- Find the efficiency of block-diagonal system and cell utilization at the same time. In this case CGE (Eq. 13) will be rewritten to include Eq. (8) inside the CGE formula as shown in Eq. (15).

- Find the efficiency of block-diagonal system and cell indicator at the same time. In this case CGE (Eq. 13) will be rewritten to include Eq. (9) inside the CGE formula as shown in Eq. (17).

- Find the efficiency of block-diagonal system and machine utilization at the same time. In this case CGE (Eq. 13) will be rewritten to include Eq. (2) inside the CGE formula as shown in Eq. (19).

- Find the efficiency of block-diagonal system and cell flexibility at the same time. In this case CGE (Eq. 13) will be rewritten to include Eq. (10) inside the CGE formula as shown in Eq. (21).

2. Used as any other grouping measure to find the efficiency of block-diagonal system (Eq. 13). The superiority of CGE is that the efficiency of block-diagonal system, the efficiency of sub-system, sparsity index and efficacy index can be found at the same time as shown in Eqs. (13-14). Without knowing the efficiency of sub-systems (individual cells), the system designer will not be able to control the cell size.

\subsection{Comparative study of different grouping measures}

In this section, we compare between the groupings measures mentioned in section 2 through a case study from the literature and analyze their corresponding results. 


\section{Problem 1:}

Consider the solution matrix of Table 3, 4 and Table 5, taken from the literature (Kusiak \& Chow, 1987).

Table 3

Final solution matrix $\mathrm{X}$ for problem 1

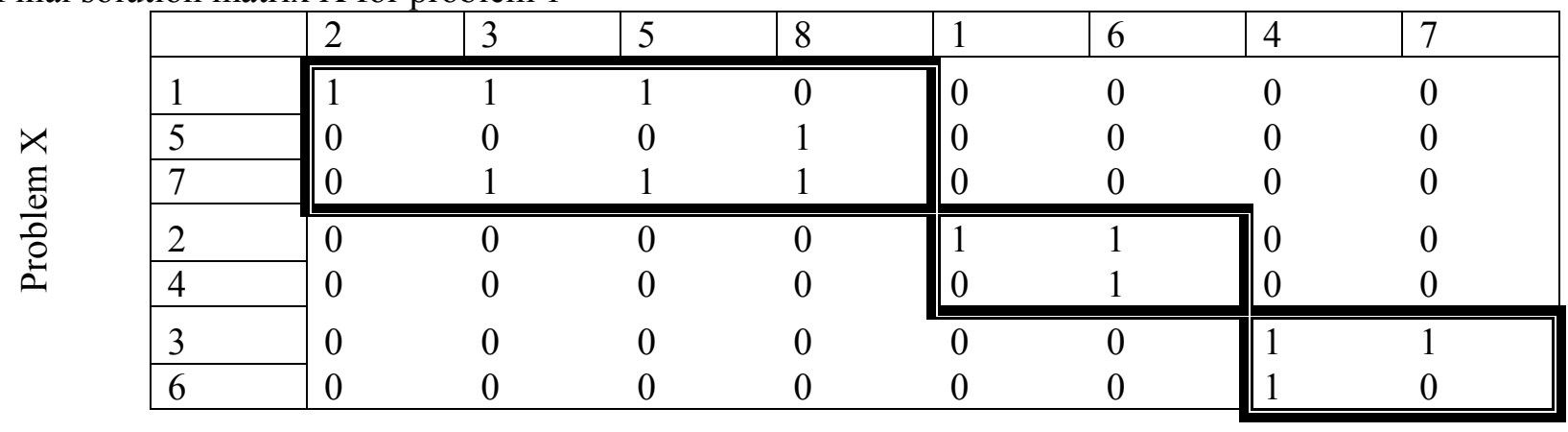

Table 4

Final solution matrix Y for problem 1

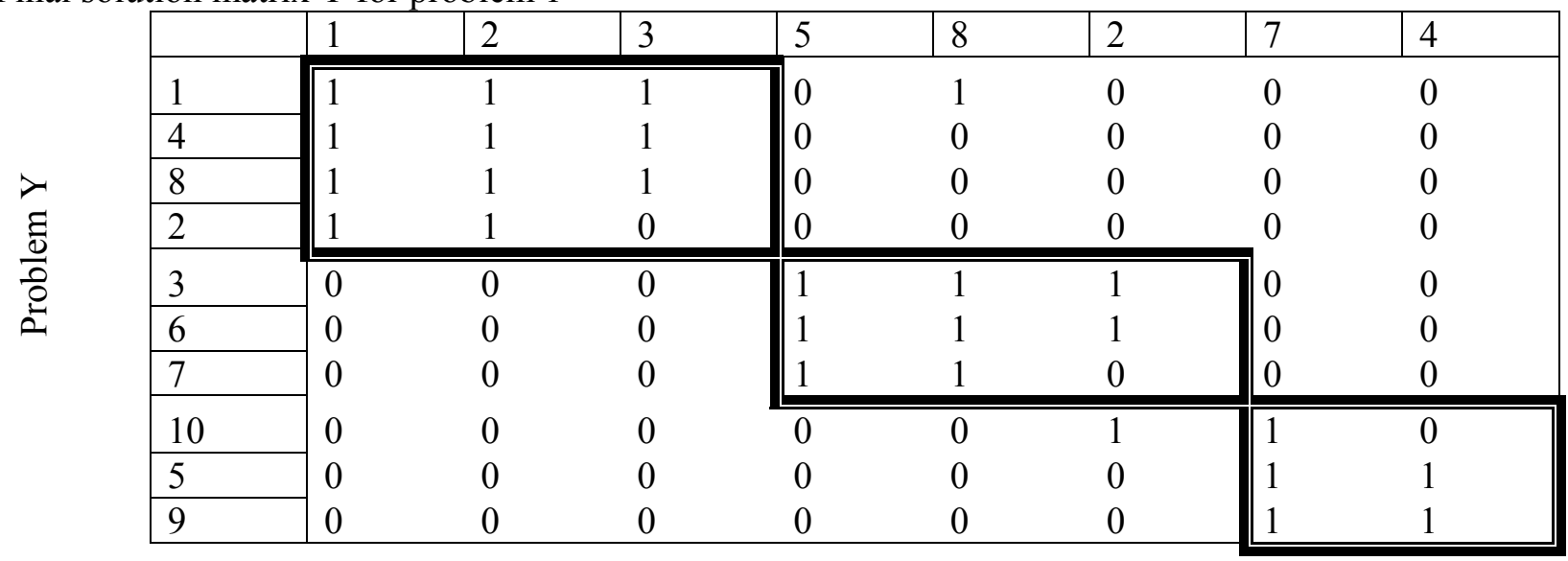

Table 5

Final solution matrix $\mathrm{Z}$ for problem 1

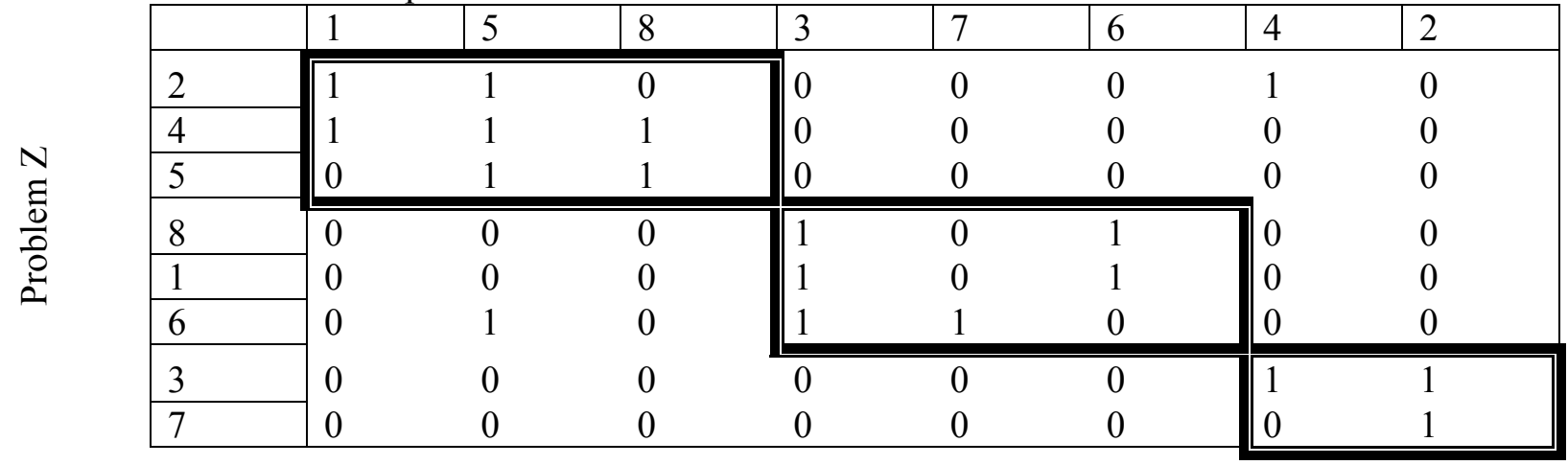

Applying the different measures of goodness discussed earlier to evaluate the quality of the above different solutions, the results are obtained and summarized in Table 6 and Table 7 . 
Table 6

Evaluation of different measures for problem 1(efficiency of block-diagonal form $)(\mathrm{q}=0.5)$

\begin{tabular}{|c|c|c|c|c|c|c|c|c|c|c|c|c|c|}
\hline Table & $\begin{array}{c}\# \\
\text { machines } \\
\text { in } 1^{\text {st }} \text { cell }\end{array}$ & $\begin{array}{c}\# \\
\text { machines } \\
\text { in } 2^{\text {nd }} \\
\text { cell }\end{array}$ & $\begin{array}{c}\# \\
\text { machines } \\
\text { in } 3^{\text {rd }} \text { cell }\end{array}$ & $\begin{array}{l}\text { \# parts } \\
\text { in } 1^{\text {st }} \\
\text { cell }\end{array}$ & $\begin{array}{c}\# \text { parts } \\
\text { in } 2^{\text {nd }} \\
\text { cell }\end{array}$ & $\begin{array}{c}\# \\
\text { parts } \\
\text { in } 3^{\text {rd }} \\
\text { cell }\end{array}$ & $\mathbf{e}+\mathbf{v}$ & $\eta$ & $\tau$ & $\gamma$ & $\omega$ & $\tau_{2}$ & MU \\
\hline 3 & 3 & 2 & 2 & 4 & 2 & 2 & 7 & 82.5 & 65 & 70.21 & 65 & 70.21 & 0.65 \\
\hline 4 & 4 & 3 & 3 & 3 & 3 & 2 & 5 & 92.32 & 82.76 & 83.10 & 82.7 & 89.8 & 0.88 \\
\hline 5 & 3 & 3 & 2 & 3 & 3 & 2 & 8 & 83.98 & 66.67 & 69.23 & 66.67 & 69.23 & 0.72 \\
\hline
\end{tabular}

From Table 6, it is clear that there is a big difference between the grouping measures in the final results. In previous studies, it is considered that grouping efficacy is considered to be the most used measure. None of these measures takes into account the efficiency of individual cells inside the system. Cell size is not taken into considerations on these measures, for such reasons these measures do not reflect the efficiency of individual cells in truthful way. In other words the sparsity of individual cells in the solved matrix is not taken into considerations.

Table 7

Evaluation of different measures for problem 1 (evaluation of individual cells)

\begin{tabular}{|c|c|c|c|c|c|c|c|c|c|c|c|c|c|c|c|c|}
\hline \multirow[t]{2}{*}{ Table } & \multirow[t]{2}{*}{$\begin{array}{c}\# \\
\text { machines } \\
\text { in } 1^{\text {st }} \\
\text { cell }\end{array}$} & \multirow[t]{2}{*}{$\begin{array}{c}\# \\
\text { machines } \\
\text { in } 2^{\text {nd }} \\
\text { cell }\end{array}$} & \multirow[t]{2}{*}{$\begin{array}{c}\# \\
\text { machines } \\
\text { in } 3^{\text {rd }} \text { cell }\end{array}$} & \multirow[t]{2}{*}{$\begin{array}{c}\# \\
\text { parts } \\
\text { in } 1^{\text {st }} \\
\text { cell }\end{array}$} & \multirow[t]{2}{*}{$\begin{array}{c}\# \\
\text { parts } \\
\text { in } 2^{\text {nd }} \\
\text { cell }\end{array}$} & \multirow[t]{2}{*}{$\begin{array}{c}\# \\
\text { parts } \\
\text { in } 3^{\text {rd }} \\
\text { cell }\end{array}$} & \multirow[t]{2}{*}{$\mathrm{e}+\mathrm{v}$} & \multicolumn{3}{|c|}{ Cell Utilization (CU) } & \multicolumn{3}{|c|}{ Cell Indicator $(\alpha)$} & \multicolumn{3}{|c|}{$\begin{array}{c}\text { Average Measure of } \\
\text { Flexibility (AMF) }\end{array}$} \\
\hline & & & & & & & & $\mathrm{CU}_{1}$ & $\overline{\mathrm{CU}_{2}}$ & $\mathrm{CU}_{3}$ & $\mathrm{CU}_{1}$ & $\overline{\mathrm{CU}_{2}}$ & $\mathrm{CU}_{3}$ & $\mathrm{CU}_{1}$ & $\mathrm{CU}_{2}$ & $\mathrm{CU}_{3}$ \\
\hline 3 & 3 & 2 & 2 & 4 & 2 & 2 & 7 & 0.580 & 0.750 & 0.750 & 0.714 & 0.33 & 0.33 & $11.6 \%$ & $5 \%$ & $5 \%$ \\
\hline 4 & 4 & 3 & 3 & 3 & 3 & 2 & 5 & 0.916 & 0.888 & 0.833 & 0.0909 & 0.375 & 0.2 & $13.56 \%$ & $9.8 \%$ & $6.11 \%$ \\
\hline 5 & 3 & 3 & 2 & 3 & 3 & 2 & 8 & 0.777 & 0.666 & 0.750 & 0.428 & 0.50 & 0.66 & $10.6 \%$ & $9.06 \%$ & $4.33 \%$ \\
\hline
\end{tabular}

Table 7 shows different measures to find the utilization, efficiency and flexibility of the cells inside the solved matrix. None of these measures reflected the efficiency of block-diagonal form. Moreover, none of them either in Table 6 or Table 7 could find both system efficiency and evaluate the individual cells in one formula.

\section{Proposed Measure}

\subsection{Comprehensive Grouping Efficacy}

In this section, a new grouping measure called Comprehensive Grouping Efficacy (CGE) is proposed to overcome these limitations. The new grouping measure can be expressed as:

$$
\begin{aligned}
& C G E=\frac{B_{j}}{B} \sum_{j=1}^{p} \frac{k_{j}}{k_{j}+v_{j}+e_{j}} \\
& C G E=\frac{B_{1}}{B}\left[\frac{k_{1}}{k_{1}+v_{1}+e_{1}}\right]+\frac{B_{2}}{B}\left[\frac{k_{2}}{k_{2}+v_{2}+e_{2}}\right]+\ldots+\frac{B_{p}}{B}\left[\frac{k_{p}}{k_{p}+v_{p}+e_{p}}\right]
\end{aligned}
$$

where $B_{1}, B_{2}, B_{p}$ and $B$ represent the sparsity of the first, the second and the $\mathrm{p}^{\text {th }}$ cell in the solved matrix, respectively. Also, $B$ represents the sparsity of the solved matrix, which is defined as the total number of elements within diagonal blocks of the solve matrix. Here $B$ represents the sparsity of the solved matrix and $B_{1}=n_{1} \times m_{1}, B_{2}=n_{2} \times m_{2}$ and $B_{p}=n_{p} \times m_{p}$. Let $\alpha_{1}=B_{1} / B, \alpha_{2}=B_{2} / B$ and $\alpha_{p}=B_{p} / B$ represent the 
sparsity index of the first, the second and the $\mathrm{p}^{\text {th }}$ cells, respectively. Let $\tau_{1}=\frac{k_{1}}{k_{1}+v_{1}+e_{1}}, \tau_{2}=\frac{k_{2}}{k_{2}+v_{2}+e_{2}}$ and $\tau_{p}=\frac{k_{p}}{k_{p}+v_{p}+e_{p}}$ represent the efficacy index of the first, the second and $\mathrm{p}^{\text {th }}$ cell, respectively with

$$
C G E=\alpha_{1} \tau_{1}+\alpha_{2} \tau_{2}+\ldots \ldots .+\alpha_{p} \tau_{p}
$$

where $\alpha_{1} \tau_{1}, \alpha_{2} \tau_{2}$ and $\alpha_{\mathrm{p}} \tau_{\mathrm{p}}$ represent the efficiency of the first, the second and he $\mathrm{p}^{\text {th }}$ cell, respectively. Here we have,

$m=$ total number of parts in the matrix,

$n=$ total number of machines in the matrix,

$m_{p}=$ number of parts in the $j t h$ diagonal block [jth cell],

$n_{p}=$ number of machines in the $j t h$ diagonal block [jth cell],

$v_{p}=$ number of voids in the $j$ th diagonal block,

$e_{p}=$ number of exceptional elements in the $j t h$ off-diagonal block,

$k_{p}=$ number of operations in the $j t h$ diagonal block,

$p=$ total number of diagonal blocks [total number of cells in the matrix].

From the definition of CGE, it is clear that this new measure reflects the goodness of every cell by taking into consideration the number of operations, number of voids, number of exceptional parts, cell size (sparsity of individual cell in the solved matrix) and sparsity of the system regardless of the size of the matrix. Since CGE is the sum of efficiency of all individual cells, then the designer can discover which cell has the smallest efficiency, which will help him to control the cell size.

\subsection{Mathematical Properties of Comprehensive Grouping Efficacy function}

1. Non negativity: All the elements of comprehensive grouping measure are positive.

2. Physical meaning of extremes:

a. When all the ones in the perfect diagonal- block are outside the diagonal block

[condition of zero efficiency], then $\mathbf{C G E}=0$ because $k_{1}=k_{2}=\ldots .=k_{\mathrm{p}}=0$.

b. For perfect diagonal block [condition of $100 \%$ efficiency], then $\mathbf{C G E}=1$ because

$v_{1}=v_{2}=v_{\mathrm{p}}=0$, and

$e_{1}=e_{2}=e_{\mathrm{p}}=0$

and $B=B_{1}+B_{2}+\ldots . .+B_{\mathrm{p}}$, then $\mathbf{C G E}=1$

c. From property 1 and property 2 it is found that $0 \leq \mathbf{C G E} \leq 1$.

\subsection{Superiority of the Comprehensive Grouping Efficacy}

In this section, we highlight the merits of CGE comparing to the other measures.

1. CGE measure (Eq.13) can be used to find the efficiency of block-diagonal form, the efficiency of sub-system, sparsity index and efficacy index at the same time. Any one of these three indicators (efficiency of sub-system, sparsity index and efficacy index) will give the system designer the opportunity to control the cell size.

- Comprehensive Grouping Efficacy measure (CGE)

CGE measure (Eq. 13) can be used as any other grouping efficiency measure to evaluate block-diagonal forms in group technology.

- Sparsity Index $\left(\alpha_{p}\right)$

It is defined as the ratio of the sparsity of sub-system to the system sparsity. The importance of sparsity index is that it reflects the impact of every cell size to the sparsity 
of the solved matrix, which will help the designer control the cell size through reformation of manufacturing systems, machines allocation or part assignment. As the sparsity index increases, the efficiency of individual cell will increase.

- Efficacy Index $\left(\tau_{\mathrm{p}}\right)$

It reflects the number of operations for cell $j$ to the size of cell $j$ and the number of exceptions belongs to cell $j$. Knowing efficacy index will help the designer know the voids, exceptions and number of operations in each cell. Then cell size can be controlled through part assignment. Part assignment is performed to minimize the number of voids inside the cells and number of ones outside the cells. This approach gives the system designer the ability to control the lower and/or the upper bound of cell size.

- Efficiency of sub-system (individual cells in the solved matrix).

It is defined as Sparsity Index $\left(\alpha_{p}\right)$ multiplied by Efficacy Index $\left(\tau_{\mathrm{p}}\right)$. The efficiency of individual cell is calculated based on the impact of cell size, sparsity of the solved matrix and number of operations inside the cell. In this case the designer has three choices to control the cell size if the efficiency of the cell is too low.

2. CGE formula(Eq. 13) is a comprehensive measure since it can be rewritten in four different forms that can be used to find:

- The efficiency of block-diagonal system and cell utilization at the same time by using only one formula (Eq. 16) since this equation contains the cell utilization measure (Eq. 8).

- The efficiency of block-diagonal system and cell indicator at the same time by using only one formula (Eq. 17) since this equation contains the cell indicator measure (Eq. 9).

- The efficiency of block-diagonal system and machine utilization at the same time by using only one formula (Eq. 19) since this equation contains the machine utilization measure (Eq. 2).

- The efficiency of block-diagonal system and cell flexibility at the same time by using only one formula (Eq. 21) since this equation contains the cell flexibility measure (Eq. $10)$.

\subsubsection{Derivation of cell utilization measure from CGE formula}

CGE measure can be rewritten as shown in Eq. (16). This formula contains the formula of cell utilization measure (Eq. 8). Eq. (16) can be used to find the efficiency of the main system and cell utilization at the same time as shown below in section 3.3.6.

$$
C G E=\frac{k_{1}}{B_{1}} \times \frac{k_{1} B_{1}+v_{1} B_{1}}{k_{1} B+v_{1} B+e_{1} B}+\frac{k_{2}}{B_{2}} \times \frac{k_{2} B_{2}+v_{2} B_{2}}{k_{2} B+v_{2} B+e_{2} B}+\ldots+\frac{k_{p}}{B_{p}} \times \frac{k_{p} B_{p}+v_{p} B_{p}}{k_{p} B+v_{p} B+e_{p} B}
$$

Let $C U_{1}=\frac{k_{1}}{B_{1}}, C U_{2}=\frac{k_{2}}{B_{2}}$ and $C U_{p}=\frac{k_{p}}{B_{p}}$, where $\mathrm{CU}_{1}, \mathrm{CU}_{2}$ and $C \mathrm{C}_{\mathrm{p}}$ represent the utilization of the first, the second and $\mathrm{p}^{\text {th }}$ cell, respectively. Let $B_{1}=k_{1}+v_{1}, B_{2}=k_{2}+v_{2}$ and $B_{p}=k_{p}+v_{p}$. Then CGE can be rewritten as follows,

$$
C G E=\frac{k_{1}}{B_{1}} \times \frac{B_{1}^{2}}{B\left(k_{1}+v_{1}+e_{1}\right)}+\frac{k_{2}}{B_{2}} \times \frac{B_{2}^{2}}{B\left(k_{2}+v_{2}+e_{2}\right)}+\ldots+\frac{k_{p}}{B_{p}} \times \frac{B_{p}^{2}}{B\left(k_{p}+v_{p}+e_{p}\right)}
$$




\subsubsection{Derivation of cell indicator measure from CGE formula}

CGE measure can be rewritten as shown below in Eq. (17). This formula contains the formula of cell indicator measure (Eq. 9). Eq. (17) can be used to find the efficiency of the main system, sparsity index and cell indicator at the same time as shown below in section 3.3.7.

$$
C G E=\frac{B_{1}}{B}\left[\frac{1}{1+\frac{v_{1}+e_{1}}{k_{1}}}\right]+\frac{B_{2}}{B}\left[\frac{1}{1+\frac{v_{2}+e_{2}}{k_{2}}}\right]+\ldots \ldots+\frac{B_{p}}{B}\left[\frac{1}{1+\frac{v_{p}+e_{p}}{k_{p}}}\right] .
$$

Let $\beta_{1}=\frac{v_{1}+e_{1}}{k_{1}}, \beta_{2}=\frac{v_{2}+e_{2}}{k_{2}}$ and $\beta_{p}=\frac{v_{p}+e_{p}}{k_{p}}$ where $\beta_{1}, \beta_{2}$ and $\beta_{\mathrm{p}}$ are cell indicators of the first, the second and the $\mathrm{p}^{\text {th }}$ cell, respectively. In addition, $\alpha_{1}=B_{1} / B, \alpha_{2}=B_{2} / B$ and $\alpha_{p}=B_{p} / B$ are sparsity index of the first, the second and the $\mathrm{p}^{\text {th }}$ cell, respectively. Therefore, we have

$$
C G E=\frac{\alpha_{1}}{1+\beta_{1}}+\frac{\alpha_{2}}{1+\beta_{2}}+\ldots \ldots . .+\frac{\alpha_{p}}{1+B_{p}} .
$$

\subsubsection{Derivation of machine utilization measure from CGE formula}

CGE measure can be rewritten as shown below in Eq. (19). This formula contains the formula of machine utilization measure (Eq. 2). Eq. 19 can be used to find the efficiency of the main system and machine utilization at the same time as shown below in section 3.3.8.

$$
C G E=\frac{k_{1}+k_{2}+. .+k_{P}}{B}\left[\frac{k_{1} \times B_{1}}{k_{1}+v_{1}+e_{1}}+\frac{k_{2} \times B_{2}}{k_{2}+v_{2}+e_{2}}+. .+\frac{k_{p} \times B_{p}}{k_{p}+v_{\mathrm{p}}+e_{p}}\right] \times \frac{1}{k_{1}+k_{2}+. .+k_{P}}
$$

Let $M U=\frac{k_{1}+k_{2}+. .+k_{P}}{B}$, where $M U$ is the machine utilization.

\subsubsection{Derivation of cell flexibility measure from CGE formula}

CGE measure can be rewritten as shown below in Eq. (21). This formula contains the formula of cell flexibility measure (Eq. (10)). Eq. (21) can be used to find the efficiency of the main system and cell flexibility at the same time as shown below in section 3.3.9.

$$
\begin{aligned}
& C G E=\frac{1}{B}\left[\frac{k_{1}}{B_{1}} \times \frac{B_{1}}{\left(1+\frac{e_{1}}{B_{1}}\right)}\right]+\frac{1}{B}\left[\frac{k_{2}}{B_{2}} \times \frac{B_{2}}{\left(1+\frac{e_{2}}{B_{2}}\right)}\right]+. .+\frac{1}{B}\left[\frac{k_{P}}{B_{P}} \times \frac{B_{P}}{\left(1+\frac{e_{P}}{B_{P}}\right)}\right] \\
& C G E=\frac{k_{1}}{B}\left[\frac{1}{1+\frac{e_{1}}{B_{1}}}\right]+\frac{k_{2}}{B}\left[\frac{1}{1+\frac{e_{2}}{B_{2}}}\right]+\ldots+\frac{k_{P}}{B}\left[\frac{1}{1+\frac{e_{P}}{B_{P}}}\right]
\end{aligned}
$$

Let $M F_{1}=\frac{k_{1}}{B}, M F_{2}=\frac{k_{2}}{B}$ and $M F_{P}=\frac{k_{P}}{B}$ where $M F_{1}, M F_{2}$ and $M F_{p}$ represent the flexibility of the first, second and $\mathrm{p}^{\text {th }}$ cell. Let $\alpha_{1}=\frac{1}{1+\frac{e_{1}}{B_{1}}}, \alpha_{2}=\frac{1}{1+\frac{e_{2}}{B_{2}}}$ and $\alpha_{p}=\frac{1}{1+\frac{e_{P}}{B_{P}}}$ then

$$
C G E=M F_{1} \alpha_{1}+M F_{2} \alpha_{2}+\ldots .+M F_{p} \alpha_{p} .
$$

Therefore the average measure of flexibility of the cells can be calculated as follows, 


$$
C G E=A M F_{1} \alpha_{1}+A M F_{2} \alpha_{2}+\ldots . .+A M F_{p} \alpha_{p}
$$

\subsubsection{Evaluation of the efficiency of block-diagonal system}

In this section, we assess the performance of CGE through comparing the results with other well-known measures mentioned in section 2. Eq. (13) will be used to find the efficiency of the system, sparsity index, efficacy index and efficiency of individual cells at the same time. For problem X, Table 3 will show the details of the cell locations. Table 8 below summarizes the results.

$$
C G E=\frac{12}{20}\left[\frac{7}{7+5+0}\right]+\frac{4}{20}\left[\frac{3}{3+1+0}\right]+\frac{4}{20}\left[\frac{3}{3+1+0}\right]=0.65
$$

In the same way we can find CGE for the other two problems (Problem Y, Table 4 and Problem Z, Table 5).

Table 8

\begin{tabular}{|c|c|c|c|c|c|c|c|c|c|c|c|}
\hline \multirow[t]{2}{*}{ Table } & \multirow[t]{2}{*}{ problem } & \multirow{2}{*}{$\begin{array}{l}\text { Efficiency of } \\
\text { block -diagonal } \\
\text { system (CGE) }\end{array}$} & \multicolumn{3}{|c|}{ Sparsity Index } & \multicolumn{3}{|c|}{ Efficacy Index } & \multicolumn{3}{|c|}{$\begin{array}{c}\text { Efficiency of individual cells } \\
\text { (sub-systems) }\end{array}$} \\
\hline & & & Cell 1 & Cell 2 & Cell 3 & Cell 1 & Cell 2 & Cell 3 & Cell 1 & Cell 2 & Cell 3 \\
\hline 3 & $\mathbf{X}$ & 0.650 & 0.6 & 0.2 & 0.2 & 0.5833 & 0.75 & 0.75 & 0.35 & 0.15 & 0.15 \\
\hline 4 & $\mathbf{Y}$ & 0.835 & 0.444 & 0.333 & 0.222 & 0.9166 & 0.7272 & 0.8333 & 0.4074 & 0.2424 & 0.185 \\
\hline 5 & $\mathbf{Z}$ & 0.668 & 0.4091 & 0.409 & 0.1818 & 0.7 & 0.666 & 0.6 & 0.286 & 0.2727 & 0.11 \\
\hline
\end{tabular}

Efficiency of the system and sub-system, Sparsity index, Efficacy index, using CGE for problem 1

Consider the solution matrix of Table 8; it is clear that there is a consistency between these indicators. For example in Table 8, the small values of sparsity index for cell 2 and cell 3 means that these cells have small size, and in this case the designer can specify the upper and lower limit of machines to be allocated to each cell or to make part assignment. Moreover, efficacy index and the efficiency of individual cells gave the same results regarding cell 2 and cell 3 . This means that cell 1 has the highest efficiency, while cell 2 and cell 3 has the lowest efficiency. As mentioned above any one of these three indicators (the efficiency of sub-system, sparsity index and efficacy index) will give the designer the opportunity to discover the cell that has the lowest efficiency in order to control the size. Without knowing the efficiency of sub-systems (individual cells), the system designer will not be able to control the cell size. Also the efficiency of block-diagonal system in this table (Table 8) using CGE grouping measure is very close to some well-known measures in Table 6.The superiority of CGE measure is that three cell indicators can be found concurrently with the efficiency of block-diagonal system.

\subsubsection{Finding Cell Utilization using the CGE Formula}

Eq. (16) will be used to find the efficiency of the system and cell utilization at the same time. Problem $\mathrm{X}$ Table 3 will be solved in details. We have $\mathrm{CU}_{1}=0.58, \mathrm{CU}_{2}=0.75$ and $\mathrm{CU} 3=0.75$.

$$
G E=\frac{7}{12} \times \frac{(12)^{2}}{20(7+5+0)}+\frac{3}{4} \times \frac{(4)^{2}}{20(3+1+0)}+\frac{3}{4} \times \frac{(4)^{2}}{20(3+1+0)}=0.65 .
$$

In the same way, the efficiency of the system and cell utilization for problem Y, Table 4 and problem $\mathrm{Z}$, Table 5 can be found. The results are summarized below in Table 9.

Table 9

Efficiency of the system and Cell utilization using CGE for problem 1

\begin{tabular}{cccccc}
\hline Table & Problem & & \multicolumn{3}{c}{ Cell Utilization (CU) } \\
\cline { 4 - 6 } & & CGE & $\mathbf{C U}_{\mathbf{1}}$ & $\mathbf{C U}_{\mathbf{2}}$ & $\mathbf{C U}_{\mathbf{3}}$ \\
\hline $\mathbf{3}$ & $\mathbf{X}$ & $\mathbf{0 . 6 5}$ & 0.580 & 0.750 & 0.750 \\
$\mathbf{4}$ & $\mathbf{Y}$ & $\mathbf{0 . 8 3 5}$ & 0.916 & 0.888 & 0.833 \\
$\mathbf{5}$ & $\mathbf{Z}$ & $\mathbf{0 . 6 6 8}$ & 0.777 & 0.666 & 0.750 \\
\hline
\end{tabular}


It is clear that cell utilization is the same in Table 9 and Table 7. CGE is the same as in Table 8. It is clear that instead of using two formulas to find the efficiency of the system and cell utilization, we use only one formula. In this case the designer will discover which cell has the lowest utilization. While the efficiency of the system will not give him any idea about the individual cells.

\subsubsection{Finding Cell Indicator using the CGE Formula}

Eq. (17) will be used to find the efficiency of the system and cell indicator of the cells at the same time. Problem X Table 3 will be solved in details.

$C G E=\frac{12}{20}\left[\frac{1}{1+\frac{5+0}{7}}\right]+\frac{4}{20}\left[\frac{1}{1+\frac{1+0}{3}}\right]+\frac{4}{20}\left[\frac{1}{1+\frac{1+0}{3}}\right] \alpha_{1}=0.6, \alpha_{2}=0.2, \alpha_{3}=0.2$.

In the same way, the efficiency of the system and cell indicator for problem Y Table 4 and problem $\mathrm{Z}$ Table 5 can be found. The results are summarized below in Table 10.

Table 10

Efficiency of the system and Cell indicator using CGE for problem 1

\begin{tabular}{cccccc}
\hline Table & Problem & CGE & Cell Indicator ( $\beta)$ & \\
\hline & & & $\mathbf{C U}_{\mathbf{1}}$ & $\mathbf{C U}_{\mathbf{2}}$ & $\mathbf{C U}_{\mathbf{3}}$ \\
\hline $\mathbf{3}$ & $\mathbf{X}$ & $\mathbf{0 . 6 5}$ & 0.714 & 0.33 & 0.33 \\
$\mathbf{4}$ & $\mathbf{Y}$ & $\mathbf{0 . 8 3 5}$ & 0.0909 & 0.375 & 0.20 \\
$\mathbf{5}$ & $\mathbf{Z}$ & $\mathbf{0 . 6 6 8}$ & 0.428 & 0.50 & 0.66 \\
\hline
\end{tabular}

It is clear that cell indicator is the same in Table 10 and Table 7 also CGE is the same as in Table 8 . Knowing cell indicator will enable the designer to distinguish between ill-structured cell and perfectstructured cell. Moreover Eq. (17) can provide the designer with sparsity index for every cell.

\subsubsection{Finding Machine Utilization using the CGE Formula}

Eq. (19) will be used to find the efficiency of the system, machine utilization of the cells at the same time. Problem X Table 3 will be solved in details. The results are summarized below in Table 1 $C G E=\frac{7+3+3}{20}\left[\frac{7 \times 12}{7+5+0}+\frac{3 \times 4}{3+1+0}+\frac{3 \times 4}{3+1+0}\right] \times \frac{1}{7+3+3}=0.65$, which means the machine utilization is equal to 0.65 . In the same way the efficiency of the system and machine utilization for problem Y Table 4 and problem $\mathrm{Z}$ Table 5 can be found.

Table 11

Efficiency of the system and machine utilization using CGE for problem 1

Table

3
4
5

\section{CGE}

0.65
0.835
0.668

Using Eq. (19) will give the designer the same result as shown in Table 7 and Table 8.The designer can compare between the efficiency of the system and the machine utilization.

\subsubsection{Finding Cell Flexibility using the CGE Formula}

Eq. (21) will be used to find the efficiency of the system, cell flexibility at the same time. Problem X Table 3 will be solved in details.

$$
C G E=\frac{7}{20}\left[\frac{1}{1+\frac{0}{12}}\right]+\frac{3}{20}\left[\frac{1}{1+\frac{0}{4}}\right]+\frac{3}{20}\left[\frac{1}{1+\frac{0}{4}}\right]=0.65, M F_{1}=0.35, M F_{2}=0.15 \text { and } M F_{3}=0.15
$$


$A M F_{1}=\frac{0.35}{3} \times 100=11.6 \%, A M F_{2}=\frac{0.15}{3}=0.05 \times 100=5 \%$ and $A M F_{3}=\frac{0.15}{3}=0.05 \times 100=5 \%$

In the same way the efficiency of the system and cell flexibility for problem Y Table 4 and problem $\mathrm{Z}$

Table 5 can be found. The results are summarized below in Table 12.

Table 12

Efficiency of the system and average measure of flexibility using CGE for problem.1

\begin{tabular}{cccccc}
\hline & & & \multicolumn{3}{c}{ Average Measure of Flexibility (AMF) } \\
\hline Table & Problem & CGE & Cell $_{1}$ & Cell $_{2}$ & Cell $_{3}$ \\
\hline $\mathbf{3}$ & $\mathbf{X}$ & $\mathbf{0 . 6 5}$ & $11.6 \%$ & $5 \%$ & $5 \%$ \\
$\mathbf{4}$ & $\mathbf{Y}$ & $\mathbf{0 . 8 3 5}$ & $13.56 \%$ & $9.8 \%$ & $6.11 \%$ \\
$\mathbf{5}$ & $\mathbf{Z}$ & $\mathbf{0 . 6 6 8}$ & $10.6 \%$ & $9.06 \%$ & $4.33 \%$ \\
\hline
\end{tabular}

From Table 12, the designer can find the efficiency of the system and cell flexibility at the same time by using only one formula (Eq. 21) and the results are the same as in Table 7 and Table 8. Moreover, the designer can find the average measure of flexibility.

\subsection{Comparison with Some Commonly Known Grouping Efficiency Measures}

In order to evaluate the performance of the proposed measure, a comparison is performed with different case studies taken from literature and the results are given in Table 13. CGE measure is compared with six well known measures to evaluate the performace of case studies. The result of CGE measure is found to be close to some of these grouping measures. It is clear that CGE measure is sensitive to number of voids, exceptions, number of operations inside the cell, sparsity of the system and sparsity of individual cells regardless of the size of the matrix. The superiority of CGE measure over these measures is that, the designer can find the efficiency of individual cells, sparsity index and efficacy index for these cases which will give him the opportunity to control cell size. Moreover, since CGE measure can be rewritten with four different forms, then cell utilization and/or machine utilization and/or cell indicator and/or cell flexibility can be found to these cases. While the other measures can find only the efficiency of the system.

\section{Conclusion}

Some well-known grouping measures were discussed and analyzed. These performance measures have some drawbacks such as ignoring sparsity of individual cells in the solved matrix and none of these measures can evaluate the efficiency of block-diagonal system and sub-system at the same time. Moreover, none of these measures can be used as a comprehensive grouping measure. In this study, to overcome the limitations of these measures, a new measure called Comprehensive Grouping Efficacy (CGE) was presented. The approach adds the cell sparsity to its other elements in which the other measures ignore this issue, for that the efficiency of block-diagonal system and sub-system can be determined concurrently. CGE showed a better understanding of individual cells in the solved matrix, since the three cell indicators (sparsity index, efficacy index and efficiency of individual cells in the solved matrix) will help the designer control the cell size. CGE is a comprehensive grouping measure since it can be used to find the efficiency of block-diagonal system and/or cell utilization and/or machine utilization and/or cell indicator and/or cell flexibility at the same time. 


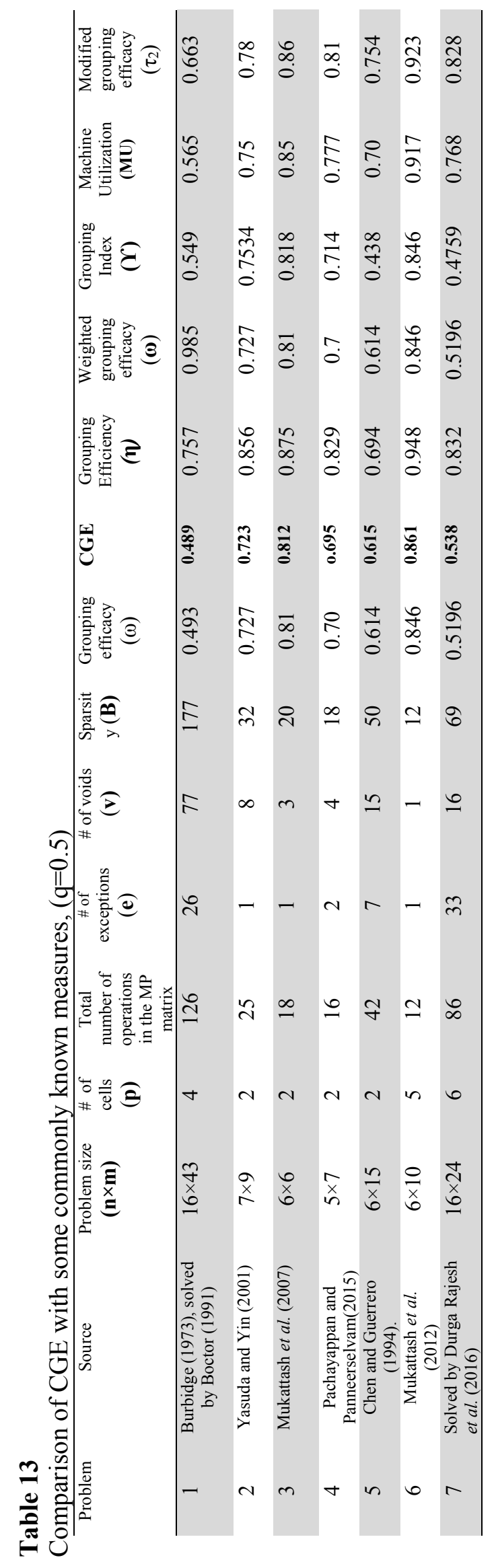




\section{Acknowledgement}

The authors would like to thank the anonymous referees for constructive comments on earlier version of this paper.

\section{References}

Al-Bashir, A. A., Mukattash, A. M., Muqattash, R. S., Al-Tal, S. Y., \& Qamar, A. M. (2016). Grouping Cell Indicator: A Modified Cell Formation Grouping Measure. Middle-East Journal of Scientific Research, 24(7), 2309-2320.

Askin, R. G., \& Chiu, K. S. (1990). A graph partitioning procedure for machine assignment and cell formation in group technology. International Journal of production Research, 28(8), 1555-1572.

Agrawal, A. K., Bhardwaj, P., \& Srivastava, V. (2011). On some measures for grouping efficiency. The International Journal of Advanced Manufacturing Technology, 56(5-8), 789-798.

Boctor, F.F. (1996). The minimum-cost, machine-part cell formation problem. International Journal of Production Research, 34(4), 1045-1063.

Boctor, F. F. (1991). A linear formulation of the machine-part cell formation problem. International Journal of Production Research, 29(2), 334-356.

Bottani, E., Centobelli, P., Cerchione, R., Gaudio, L., \& Murino, T. (2017). Solving machine loading problem of flexible manufacturing systems using a modified discrete firefly algorithm. International Journal of Industrial Engineering Computations, 8(3), 363-372.

Burbidge, J. L. (1973), Production flow analysis on a computer. Third Annual Conference of the Institute of Production Engineers.

Bychkov, I., Batsyn, M., \& Pardalos, P. M. (2014). Exact model for the cell formation problem. Optimization Letters, 8(8), 2203-2210.

Brusco, M.J. (2015), An exact algorithm for maximizing grouping efficacy in Part machine clustering. IIE Transactions, 47(6), 653-671.

Chandrasekharan, M. P., \& Rajagopalan, R. (1986 a) An ideal seed non-hierarchical clustering algorithm for cellular manufacturing. International Journal of Production Research, 24(2), 451464.

Chandrasekharan, M., \& Rajagopalan, R. (1986). MODROC: an extension of rank order clustering for group technology. International Journal of Production Research, 24(5), 1221-1233.

Chen, H. G., \& Guerrero, H. H. (1994). A general search algorithm for cell formation in group technology. International Journal of Production Research, 32(11), 2711 - 2724.

Elbenani, B., \& Ferland, J. A. (2012). Cell formation problem solved exactly with the dinkelbach algorithm, Montreal. Quebec. CIRRELT-2012-07, pp. 114

Harhalakis, G., Nagi, R., \& Proth, J. M. (1990). An efficient heuristic in manufacturing cell formation for group technology applications. The International Journal of Production Research, 28(1), 185-198.

Ghosh, T., B., Doloi, P. K., Dan. (2014). A novel cell formation technique in cellular manufacturing system based on production factors, $5^{\text {th }}$ International \& 26th All India Manufacturing Technology, Design and Research Conference (AIMTDR 2014), IIT Guwahati, Assam, India.

Hsu, C.P. (1990). Similarity coefficient approaches to machine-component cell formation in cellular manufacturing: a comparative study. PhD thesis, Industrial and Systems Engineering, University of Wisconsin- Milwaukee.

Keeling, K. B., Brown, E. C., \& James, T. L. (2007). Grouping efficiency measures and their impact on factory measures for the machine-part cell formation problem: A simulation study. Engineering Applications of Artificial Intelligence, 20(1), 63-78.

Lee, K., \& Ahn, K. I. (2013). GT efficacy: a performance measure for cell formation with sequence data. International Journal of Production Research, 51(20), 6070-6081.

Kusiak, A., \& Chow, W. S. (1987). Efficient solving of the group technology problem. Journal of manufacturing systems, 6(2), 117-124. 
Mahdavi, I., Javadi, B., Fallah-Alipour, K., \& Slomp, J. (2007). Designing a new mathematical model for cellular manufacturing system based on cell utilization. Applied Mathematics and Computation, 190(1), 662-670.

Mansouri, S. A., Husseini, S. M., \& Newman, S. T. (2000). A review of the modern approaches to multicriteria cell design. International Journal of Production Research, 38(5), 1201-1218.

Mukattash, A. M., Abbasi, G. Y., Tahboub, K. K., \& Adil, M. B. (2006). A modified revised P-median approach to cell formation. International Journal of Industrial and Systems Engineering, 2(1), 51-60.

Mukattash, A. M., Tahboub, K. K., Fouad, R. H., \& Al-Bashir, A. A. (2011). A unified approach for designing a cellular manufacturing system by specifying number of cells. International Journal of Applied Mathematics and Statistics, 27(3).

Miltenburg, J., \& Zhang, W. (1991). A comparative evaluation of nine well-known algorithms for solving the cell formation problem in group technology. Journal of Operations Management, 10(1), 44-72.

Murugan, M., \& Selladurai, V. (2011). Formation of machine cells/part families in cellular manufacturing systems using an ART-modified single linkage clustering approach - a comparative study. Jordan Journal of Mechanical and Industrial Engineering, 5(3), 199-212.

Nagendra Parashar, B.S. (2004c), Evaluation of cellular manufacturing systems design- VEDO Analysis, Industrial Engineering Journal, 33(6), June ,pp.4-8.

Nair, G. J. K., \& Narendran, T. T. (1996). Grouping index: a new quantitative criterion for goodness of block-diagonal forms in group technology. International Journal of Production Research, 34(10), 2767-2782.

$\mathrm{Ng}$, S. M. (1993). Worst-case analysis of an algorithm for cellular manufacturing. European Journal of Operational Research, 69(3), 384-398.

Pachayappan, M., \& Panneerselvam, R. (2015). Hybrid Genetic Algorithm for Machine-Component Cell Formation. Intelligent Information Management, 7(03), 107.

Rabbani, M., Elahi, S., \& Javadi, B. (2017). A comprehensive quadratic assignment problem for an integrated layout design of final assembly line and manufacturing feeder cells. Decision Science Letters, 6(2), 165-192.

Rajesh, K. D., Chalapathi, P. V., Chaitanya, A. B. K., Sairam, V., \& Anildeep, N. (2006). Modified grouping efficacy and new average measure of flexibility: performance measuring parameters for cell formation applications, ARPN Journal of Engineering and Applied Sciences, 11(15), 9212-9215.

Rezazadeh, H., \& Khiali-Miab, A. (2017). A two-layer genetic algorithm for the design of reliable cellular manufacturing systems. International Journal of Industrial Engineering Computations, 8(3), 315-332.

Sarker, B. R. (1999). Grouping efficiency measures in cellular manufacturing: a survey and critical review. International Journal of Production Research, 37(2), 285-314.

Sarker, B. R. (2001). Measures of grouping efficiency in cellular manufacturing systems. European Journal of Operational Research, 130(3), 588-611.

Sarker, B. R., \& Khan, M. (2001). A comparison of existing grouping efficiency measures and a new weighted grouping efficiency measure. Iie Transactions, 33(1), 11-27.

Seifoddini, H., \& Djassemi, M. (1996). A new grouping measure for evaluation of machine-component matrices. International Journal of Production Research, 34(5), 1179-1193.

Suresh Kumar, C., \& Chandrasekharan, M. P. (1990). Grouping efficacy: a quantitative criterion for goodness of block diagonal forms of binary matrices in group technology. International Journal of Production Research, 28(2), 233-243.

$\mathrm{Wu}, \mathrm{N}$. (1998). A concurrent approach to cell formation and assignment of identical machines in group technology. International Journal of Production Research, 36(8), 2099-2114.

Yasuda, K., \& Yin, Y. (2001). A dissimilarity measure for solving the cell formation problem in cellular manufacturing. Computers \& Industrial Engineering, 39(1), 1-17. 
(C) 2017 by the authors; licensee Growing Science, Canada. This is an open access article distributed under the terms and conditions of the Creative Commons Attribution (CCBY) license (http://creativecommons.org/licenses/by/4.0/). 